\title{
El poder totalitario: El caso de la revolución bolivariana
}

\author{
The Totalitarian Power: The Case of the Bolivarian Revolution
}

José J. Blanco

Departamento de Ciencias Sociales, Universidad Simón Bolívar, Venezuela

\begin{abstract}
RESUMEN
La ciencia política, la historia y la filosofía han enfocado su atención en uno de los fenómenos que han dejado una huella indeleble en el siglo XX: el totalitarismo. Los enfoques de estas disciplinas han terminado por hacer del concepto uno fundamental para el léxico político, pero han desmejorado sus rendimientos científicos. Frente a esta situación, se echa mano de la teoría de los sistemas con el propósito de movilizar distinciones que nos permitan hilar más fino en la observación del fenómeno totalitario. Lamentablemente, la teoría de los sistemas ofrece pocos puntos de arranque para este proyecto, lo que nos obliga a echar mano de la teoría política del totalitarismo. Allí, Claude Lefort nos ayudará a descubrir que el totalitarismo hace referencia a la constitución paradójica del sistema político, resultando una forma de autodescripción tautológica. Esta autodescripción se hace programa político, afectando la codificación, la inflación organizacional, simbólica e instrumental del medio, así como la reproducción autopoiética, a través del acortamiento de los horizontes de sentido. Todo este instrumental teórico nos sirve para demostrar, en el caso de la revolución bolivariana, cómo los totalitarismos evolucionan y se adaptan a diversos contextos políticos.
\end{abstract}

Palabras Clave: Totalitarismo; Poder; Medios de consecución; Autodescripción tautológica; Revolución bolivariana

ABSTRACT

Political science, history and philosophy have focused their attention at one of the most striking phenomena during the twentieth century: totalitarianism. These disciplines have made of totalitarianism a fundamental concept, but unexpectedly they have also underscored its scientific poignancy. Facing this scenario, it will be handed on the systems theory with the purpose of mobilizing distinctions which allow us to search deeper into the totalitarian phenomenon. Unfortunately, systems theory itself offer few departure points for this project, which enforces us to hand on the political theory of totalitarianism. Within this realm, Claude Lefort will help us to discover that totalitarianism refers to the paradox constitution of the political system, resulting in a form of tautological self-description. This kind of self-description becomes a political program affecting coding, symbolic, instrumental and organizational inflation of the medium and, through the shortening of the sense-making horizons, the autopoietic reproduction as well. All of these theoretical improvements would serve us to demonstrate how, in the case of the Bolivarian revolution, totalitarianisms evolve and adapt to different political contexts.

KEYWORDS: Totalitarianism; Power; Success media; Tautological self-description; Bolivarian revolution

\footnotetext{
REVISTA MAD - REVISTA DEL MAGÍSTER EN ANÁLISIS SISTÉMICO APLICADO A LA SOCIEDAD ISSN 0718-0527

Facultad de Ciencias Sociales, Departamento de Antropología.

Universidad de Chile

www.revistamad.uchile.cl
}

DOI: http://dx.doi.org/10.5354/0718-0527.2016.40615 


\section{INTRODUCCIÓN}

El totalitarismo es sin duda un concepto fundamental para comprender el siglo $X X$; bien sea que se le considere como una nueva forma de gobierno o una tiranía con medios modernos (medios de difusión como la radio y técnicas de comunicación como la propaganda) a su disposición, se trata de un conjunto de experiencias globales que han dejado una huella profunda en la historia contemporánea. Pero, ¿ha quedado el totalitarismo como cosa del pasado?

Esta no es una pregunta fácil de responder, por varias razones. En primer lugar, se trata de un concepto que en su historia ha oscilado entre la ciencia y el discurso político, con lo que ha pagado con ambigüedad su capacidad comunicativa. Se ha empleado políticamente como arma de lucha, usada con el objeto de desacreditar al rival y desvestirlo de toda legitimidad (Rabinbach 2006). En consecuencia, la ciencia política ha demostrado una tendencia a abandonar el concepto de totalitarismo, tomándolo como una particularidad histórica, y se ha aferrado al concepto más amplio de autoritarismo. En segundo lugar, si bien desde la filosofía, la ciencia política y la historia se han realizado sendos esfuerzos por comprender el fenómeno, la selectividad de cada disciplina ha dificultado la construcción de una definición consensuada. La filosofía tiende a reducirlo todo a una esencia o principio (principios atemporales o sujetos a un Zeitgeist), sea que éste se halle en la naturaleza humana o en la naturaleza de las cosas; la ciencia política parte de taxonomías que construye a partir de una rigurosa observación del fenómeno y eleva pretensiones analíticas y comparativas; y la historia busca comprender los fenómenos en su especificidad, hallando aquello que los hace únicos -de hecho, en la historiografía es más frecuente encontrar el concepto de fascismo que el de totalitarismo, pues desde que éste ingresó a la comunicación científica, hizo carrera como concepto comparativo de las experiencias nacionalsocialistas y soviéticas. En tercer lugar -lo que nos parece fundamental- porque a la ciencia política le ha faltado una adecuada concepción del poder. Nos explicamos.

Tanto en la historia como en la ciencia política la construcción de categorías de análisis carece de abstracción suficiente como para delimitar con claridad los conceptos (la semántica objeto de observación científica) de las categorías (diferencias trazadas por el observador). Esto trae como consecuencia que el significante (en este caso la palabra totalitarismo) se cargue con excedentes de referencias de sentido y adquiera tal 
complejidad que se haga indispensable en el repertorio semántico de una sociedad cada vez más compleja. Desde este punto de vista, los rendimientos son positivos para el sistema social, porque la comunicación encuentra redundancia y capacidad de enlace. Pero si lo que nos interesa es refinar las distinciones en un proceso comunicativo orientado por el símbolo de la verdad -y sobre todo que sean capaces de reintroducción (Luhmann 1992: 379-383) - convendría trazar distinciones cada vez más elaboradas; y justamente una distinción que nos podría orientar en esta tarea sería la que acabamos de hacer: conceptos/ categorías.

Con un arsenal teórico más sensible seríamos capaces de producir descripciones cada vez más complejas; estaríamos capacitados para observar el entorno social y cómo éste observa. Un enfoque adecuado sobre el poder, como decíamos, es fundamental pues si seguimos aferrados a los principios de la taxonomía como forma de construir categorías de análisis (distinciones), seremos incapaces de aprehender lo social en su dinámica; de modo que al definir un fenómeno lo cristalizamos, al denominarlo lo aniquilamos, dejándolo reificado como una pieza de museo; esas construcciones pierden pronto validez, porque la realidad cambia y entonces es necesario reinventarlas o crear otras nuevas.

Pero, ¿si en vez de partir de una teoría de las formas de gobierno, o de categorizaciones ad hoc de los regímenes políticos, partimos de una teoría del poder como un fenómeno evolutivo y en evolución, como una relación estratégica donde la observación y el saberse observado lleva al cambio de tácticas y estrategias y, por tanto, a la refacción de las dinámicas de poder? ¿Qué tal si concebimos al poder como un medio de comunicación simbólicamente generalizado, o para ponerlo corto, como un medio de consecución?

Desde este punto de vista, el totalitarismo sería un episodio de una variación evolutiva del poder, el cual ha exhibido distintas mutaciones, desde formas más virulentas a otras que lo son menos. El predominio de la violencia física, característico de las formas más brutales de totalitarismo, ha cedido el paso a estrategias menos visibles o escandalosas (lo cual es importante ante una opinión pública que es cada vez más internacional y cada vez más susceptible ante imágenes fuertes; donde además casi nada escapa al ojo de una cámara), pero tanto o más efectivas, como las de la violencia psicológica, el hacer a las víctimas cómplices, la oferta de bienestar material a cambio de lealtad política, entre otros. Todos estos, fenómenos que describieron los teóricos políticos de la Europa del Este como Milan Simecka, Adam Michnik, Zdenek 
Mlynar, Aleksandr Zinoviev, entre otros. Algunos llamaron a las transformaciones que sufrió la URSS tras la muerte de Stalin como postotalitarismo, pues, aunque reconocían que el terror había cedido, era irrefutable que el aparato de dominación total seguía en pie (Rupnik 1991). De allí, el concepto adquirió muchos apellidos: ilustrado, disfuncional, fracasado, autoritario, entre otros (Rabinbach 2006).

Hoy en día siguen existiendo regímenes totalitarios y no requiere gran esfuerzo reconocerlos: Corea del Norte, Cuba, Rusia, el Estado Islámico y Venezuela. Sí, Venezuela. Incluso echando mano de la teoría política del totalitarismo, podemos encontrar rasgos esenciales del totalitarismo en la revolución bolivariana. Pero para no caer en las diatribas que han marcado el debate sobre el totalitarismo, decidimos proponer un enfoque alternativo: el de la teoría de los sistemas sociales.

Sin embargo, la tarea no es sencilla. No existe una reflexión sistemática en la obra de Niklas Luhmann sobre los gobiernos no democráticos. En términos generales, podríamos decir que su reflexión sobre el tema es muy cercana al enfoque científico-político de los sistemas de partidos, por lo que éste prefiere utilizar el concepto de sistemas unipartidistas a otros conceptos como autoritarismo, fascismo, totalitarismo, entre otros. De igual modo, es palpable la influencia del caso soviético en sus escasas reflexiones sobre el tema, al punto de que en diversas ocasiones califica a la URSS como un imperio (Luhmann 2000: 269-270; 2006: 385; 1999: 101). Por último, podemos observar también la predominancia de un enfoque comparativo: los sistemas unipartidistas aparecen usualmente en comparación con los multipartidistas. Podríamos sintetizar de la siguiente manera sus principales ideas sobre el tema, las cuales encontramos dispersas a través de distintos trabajos:

- Lo primero a resaltar es la consideración de ambos tipos de sistemas de partidos como equivalentes funcionales entre sí, desde el punto de vista de sus prestaciones a la reducción de la complejidad. Al menos hasta tanto los sistemas unipartidistas dispusieren de una ideología y una organización lo suficientemente complejas para que no se perdiese sensibilidad frente al entorno ni prestación de enlace (Luhmann 2007a: 42-43). En otros lugares, apunta a la improbabilidad de que la ideología sirviese para estos logros.

- Por el momento, conviene en la importancia de la ideología para los sistemas unipartidistas como filtro para el procesamiento de la información y producción del sentido. La ideología se encuentra altamente integrada con la estructura de poder y lo característico de 
la prestación ideológica para el procesamiento del sentido es la temporalización de las contradicciones, bien sea mediante la referencia a la planificación estatal o a un futuro promisorio (Luhmann 2010: 305-315).

- El problema es que en un contexto de diferenciación funcional y alta presión temporal, si bien las administraciones socialistas habían podido funcionar satisfactoriamente (aunque sacrificando los consensos sociales), ello terminaba por arruinar la ideología (Luhmann 2007b: 149, 151-153).

- Como regla general, los sistemas unipartidistas enfrentan problemas de sensibilidad política y de capacidad de aprendizaje. Se observa una exagerada verbalización del poder. Se dificulta la difusión de verdades incómodas, tanto al interior como al exterior del partido. La sucesión se convierte en un tema vital y muy delicado. Y el poder es irreflexivo, es decir no puede limitarse con poder. Todo esto resulta en una pobre diferenciación entre administración (toma y ejecución de decisiones vinculantes colectivas) y política (preparación de los consensos y apoyos para la toma de decisiones) (Luhmann 2010: 316-320).

- En los sistemas unipartidistas no existen divergencias fundamentales en la estructura de objetivos entre el Estado y el partido (Luhmann 2007b: 75).

- En los países subdesarrollados se encuentran dos variantes de los sistemas unipartidistas, a saber, los de partido dominante y los de partido hegemónico. Característicamente estos sistemas presentan una politización de la administración, el predominio de los programas de fines y la sujeción de la estructura de poder por parte de una élite social (Luhmann 2010: 320-330).

- El hecho de que un Estado se identifique con un objetivo lo hace despótico. La razón es que con ello renuncia a la universalidad específica de la función política y desconoce la lógica de la diferenciación funcional, lo cual trae consecuencias graves, como la anulación del Estado en cuestión como destinatario de exigencias político-mundiales. Casos como éste se ven en los países socialistas, los cuales se socavan a sí mismos, pues, sus esfuerzos por mantenerse en el poder terminan por agotar sus recursos de poder, llevándolos a la ruina económica y haciéndoles perder el apoyo popular (Luhmann 1999: 135-136). 
- El partido único pretende erigirse como representante de la única opinión correcta, con lo cual la desviación se personaliza. Esta personalización de la desviación se concreta en la universalización de la sospecha, la cual instituye en toda interacción la coercitividad de la presencia de lo ausente. Esto trae como consecuencia una considerable sobre-exigencia del sistema que, desconociendo la diferenciación funcional, pretende comprometerse con toda la amplitud de lo social. (Luhmann 2000: 269-271).

- Finalmente, en aquellos casos donde la oposición es permitida a regañadientes, ésta sirve únicamente como colchón entre el gobierno y el electorado, nunca tiene la oportunidad de gobernar y por ello no tiene ocasión de disciplinarse en relación con lo que puede lograr realmente si fuese gobierno, deviniendo en lo ilusorio (Luhmann 2000: 101).

Dentro de la teoría de los sistemas existe otro aporte que es necesario considerar. Aldo Mascareño (2010) ha reformulado algunos de los conceptos principales de la teoría de los sistemas de Niklas Luhmann, con el propósito de describir la particularidad de América Latina como una región que ha desarrollado una vía propia hacia la diferenciación funcional, a saber, una diferenciación funcional concéntrica. La diferenciación funcional concéntrica se basa en la preponderancia del sistema político, cuya diseminación extrapolítica del poder afecta la autonomía operativa del resto de los sistemas funcionales, causando episodios de desdiferenciación. Al mismo tiempo, la diferenciación funcional concéntrica, a través de la operatividad de la estratificación social y la reciprocidad, diseña nuevos mecanismos de inclusión y exclusión basados en la corrupción, la coerción y la violencia.

Lo destacable del abordaje de Mascareño, es que se remite al problema de si es posible y de qué manera los medios de consecución podrían intervenir en el ámbito operativo de otros medios o sistemas causando desdiferenciación. La dificultad con la perspectiva del sociólogo chileno consiste en que sobreenfatiza la particularidad latinoamericana, sin ofrecer una diferencia convincente entre América Latina y el resto del mundo. Muchas de las reelaboraciones conceptuales del autor han podido abordarse con el arsenal teórico ya disponible, por ejemplo: ¿para qué hablar de desdiferenciación episódica si se dispone del concepto de acoplamiento operativo?; habría que indicar por lo menos cuáles son las ventajas teóricas que ofrece la primera sobre la segunda; después, introduce una diferencia entre estructura y acción, subutilizando la 
radicalidad del concepto de estructura en el marco del giro autopoiético. Finalmente, aunque el autor aborda problemas importantes como los golpes de Estado y la relación de la política con el derecho, no ofrece ninguna descripción sobre el problema del autoritarismo -y mucho menos del totalitarismo.

Así pues, dado que en la obra del mismo Luhmann y en otros abordajes sistémicos encontramos pocos puntos de anclaje, resultaría recomendable hacer una lectura sistémica de la teoría política del totalitarismo. Una vez hecho esto, podemos aventurarnos a exponer un punto de vista sistémico y socio-evolutivo del problema, tomando en cuenta las transformaciones en la estructura del medio de consecución "poder".

Organizaremos nuestra exposición como sigue: examinaremos la teoría política del totalitarismo para dar con sus problemas y potencialidades y orientarnos en la comprensión del fenómeno (1); traduciremos al lenguaje sistémico los principales problemas socioestructurales que atañen a la semántica del totalitarismo: la unidad de la diferencia del sistema político y las autodescripciones tautológicas (2); examinaremos cómo opera el sistema político bajo un programa totalitario (3) y determinaremos las transformaciones en la estructura del poder, cuando éste adopta variaciones que se han denominado totalitarias (4). En todo este recorrido, tendremos a la revolución bolivariana como caso de estudio.

\section{LA TEORÍA POLÍTICA DEL TOTALITARISMO: ESCOLLOS Y POTENCIALIDADES}

La teoría política del totalitarismo surge propiamente con la obra de Carl Friedrich y Zbigniew Brzezinski, Totalitarian Dictatorship and Autocracy (1965). Los autores pretendían darle forma a una teoría más precisa sobre el totalitarismo que superara al trabajo más filosófico de Hannah Arendt, The Origins of Totalitarianism (1951). Se decía que los filósofos andaban preocupados por las esencias sin atender al funcionamiento real de los regímenes totalitarios (Forti 2008: 86). No obstante, debido a la importancia de la obra de Arendt en la configuración de los enfoques de la ciencia política (bien sea porque se le criticase o porque se le tomase como referencia), sería pertinente iniciar escribiendo algunas palabras sobre su visión del totalitarismo.

Para Arendt, el totalitarismo es una nueva forma de gobierno que se basa en la pretensión de dominación total y a la que el terror le es 
consustancial. La máxima expresión de su pretensión de transformar la naturaleza humana, haciendo del hombre un autómata que responda solamente a los estímulos más básicos, es el campo de concentración; sólo allí se realiza plenamente su experimento de la dominación total. Las características del régimen totalitario son a grosso modo las siguientes:

- Primeramente, hay que diferenciar el movimiento del régimen. Tienen comportamientos distintos en cada fase (Arendt 2004: 408).

- Se basa en el apoyo popular, y no por ignorancia ni por lavado de cerebro (Arendt 2004: 387).

- El movimiento totalitario emplea el terror como medio de expresión del resentimiento, la frustración y el odio (Arendt 2004: 414), mientras que cuando se convierte en un Estado totalitario llega a desatarlo en su máxima furia, cuando ya ha aniquilado a la oposición organizada (Arendt 2004: 34).

- Muestran un desprecio por la realidad y los hechos; éstos son ajustados a los golpes a los postulados ideológicos y a los planes políticos (Arendt 2004: 36).

- Se establece una relación líder/ masa basada en la lealtad total, irrestricta, incondicional e inalterable del miembro individual (Arendt 2004: 405-408).

- Cuando se convierte en Estado totalitario, su estructura de poder se caracteriza por las funciones superpuestas y por la creación de organismos paralelos o duplicados de los ya existentes. Para la autora el poder totalitario, es esencialmente inestable, se halla siempre en movimiento. De esta manera, el eje de poder queda invisibilizado (Arendt 2004: 488-493).

- Empleo de la organización (el partido) como medio para la difusión de la propaganda. Los patrones de uso de la propaganda varían en sus distintas etapas, movimiento o Estado (Arendt 2004: 425-427).

- La policía secreta se convierte en la rama ejecutiva (Arendt 2004: 36-37).

- Despersonalización del enemigo, lo que permite concentrar la enemistad en un portador de tendencias, una clase o un grupo que para el momento se considere amenazante (Arendt 2004: 517-519).

- Logran que la sociedad opere con los códigos de conducta de la policía secreta: sospecha, psicología de doble-agente, provocación, complicidad con los crímenes, purgas para acceder a cargos, entre otros (Arendt 2004: 524-527). 
Las virtudes del trabajo de Arendt son su gran rigurosidad, sus análisis punzantes, su exhaustividad y el hecho de que logró sintetizar los aportes de los trabajos sobre el tema que le precedieron. Sin embargo, termina construyendo una suerte de tipo ideal basándose en los casos históricos de la Alemania nazi y la URSS stalinista, lo cual en sí mismo no es un gran inconveniente, sino la forma en que puede ser usado tanto en el estudio de los sistemas políticos comparados, como a la hora de tener en cuenta las mismas variaciones que el fenómeno puede sufrir. Sorprende que al final pretenda sintetizar el rico análisis emprendido, reduciendo el totalitarismo al terror como su esencia, de manera que si desaparece el terror -como ocurrió después de la muerte de Stalin- no se podría seguir hablando de totalitarismo, aún si puedes encontrar muchas otras características.

Cuando Friedrich y Brzezinski (1976: 34-50) publican su obra, el concepto se hallaba en descrédito debido a su ambigüedad; los autores intentaron dar una definición precisa del totalitarismo y abogaban por la utilidad del concepto para entender ciertos fenómenos políticos. El totalitarismo era una nueva forma de gobierno, aunque compartiera las pretensiones totalitaristas de las autocracias tradicionales; se trataba en cierto sentido de una autocracia ajustada a la democracia de masas y a los avances tecnológicos de la modernidad. Para estos autores, las características definitorias del totalitarismo son:

- Partido único de masas dirigido usualmente por un hombre, organizado jerárquicamente y típicamente superior o ligado con la burocracia estatal.

- Ideología proyectada hacia un estado final perfecto del hombre, a la cual todo el mundo debe adherirse, al menos pasivamente.

- Sistema de terror, sea físico o psíquico, efectuado por el partido y por la policía secreta.

- Monopolio casi completo de los medios de masas por parte del gobierno y del partido.

- Monopolio casi completo del uso efectivo de todas las armas de combate.

- Control central y dirección de toda la economía.

En 1969 Carl Friedrich, enfrentado a la revisión de la obra, agregó dos características más (Grieder 2007):

- El control monopólico se extiende para alcanzar todas las organizaciones, no sólo las económicas. 
- Este control no necesita estar en manos del partido sino de cualquier élite.

Friedrich y Brzezinski (1976: 367-443) eran críticos frente a las teorías esencialistas del totalitarismo (como la de Arendt), las cuales señalaban a la dominación total como la característica dominante del totalitarismo. Sugirieron que los totalitarismos, aunque desplegaban pretensiones de dominación total, nunca llegaban a alcanzarla (y sobre esta idea los entendidos en la materia de hoy en día suelen coincidir); por lo que propusieron el concepto de "islotes de separación", justamente para definir aquellas áreas capaces de resistir el embate totalitario.

Raymond Aron, quien desde finales de los 30 ensayaba con el concepto de religiones políticas para describir el fenómeno totalitario, publica en 1968 su Democracy and Totalitarianism. Allí establece cinco criterios que a su juicio permiten identificar un régimen totalitario:

- Partido monopolístico.

- Ideología que se convierte en la verdad oficial del Estado.

- Politización de todos los crímenes posibles, resultando en un terrorismo ideológico y policíaco.

- Doble monopolio de los medios de persuasión y coerción.

- Sujeción al Estado de la mayoría de las actividades profesionales y económicas.

Más recientemente, Juan Linz (2000) intervino en el debate sintetizando en tres características los rasgos definitorios del totalitarismo:

- Centro de poder monístico pero no monolítico, permitiendo algo de pluralismo en la base del sistema.

- Ideología exclusiva, autónoma e intelectualmente más o menos elaborada.

- Participación ciudadana en la activa movilización para la consecución de los objetivos sociales, liderados por el partido y por grupos secundarios monopolísticos.

Antes de realizar un balance de estos aportes, sería prudente tomar en consideración las obras del filósofo francés Claude Lefort y del historiador italiano Emilio Gentile, las cuales han sido bastante influyentes.

Para Lefort (1990), la política moderna está marcada por la contradicción de la política democrática. Esta contradicción consiste en que el poder emana del pueblo y que ese poder no pertenece a nadie. La democracia se trata entonces, desde un punto de vista de las 
representaciones simbólicas, de un lugar vacío. En el poder totalitario, dentro de este marco de referencias, opera una transformación simbólica, pues ahora ese lugar vacío pasará a ser ocupado por un órgano que resume en sí todas las fuerzas sociales. Ése será el líder, la síntesis del pueblo-Uno con el poder-Uno. Por su parte, el individuo quedará reducido a un hombre-pieza; un simple engranaje dentro de la gran maquinaria social.

Gentile es conocido por sostener que el fascismo italiano es totalitario, cuando la mayoría de los historiadores tienden a excluirlo de esa categoría; también ha jugado un rol importante en el reavivamiento de la categoría de religión política, como un marco conceptual estimulante para estudiar la relación entre religión y política, en donde el totalitarismo es un caso bastante llamativo (Gentile 2004). Para Gentile, el totalitarismo puede ser definido como sigue:

Un experimento de dominio político, llevado a cabo por un movimiento revolucionario, organizado en un partido rígidamente disciplinado, con una concepción integralista de la política, que aspira al monopolio del poder y que, después de haberlo conquistado, por vías legales o extralegales, destruye o transforma el régimen preexistente y construye un Estado nuevo, fundado sobre el régimen de partido único, con el objetivo principal de conseguir la conquista de la sociedad, es decir, la subordinación, la integración y la homogeneización de los gobernados, sobre la base del principio de la politicidad integral de la existencia, tanto individual como colectiva, interpretada según las categorías, los mitos y los valores de una ideología sacralizada en la forma de una religión política, con el propósito de plasmar el individuo y las masas a través de una revolución antropológica, para regenerar al ser humano y crear un hombre nuevo, dedicado en cuerpo y alma a la realización de los proyectos revolucionarios e imperialistas del partido totalitario, con el fin de crear una nueva civilización de carácter supranacional. (Gentile 2002: 81).

A continuación, resume sus aspectos fundamentales en cuatro puntos: la militarización del partido, la concentración monista, la sacralización de la política y la organización capilar de las masas. Cuatro son también sus instrumentos: la coerción, la demagogia, la pedagogía totalitaria y la discriminación del extraño (Gentile 2002: 82-83).

Todas estas definiciones han recogido algunos factores puntualizados por Arendt, tales como el rol de la ideología, el terror y el partido. No obstante, un elemento llamativo de la teorización de Arendt como lo es su teoría del poder invisibilizado e inestable, no fue tomado en 
cuenta por ningún otro autor de importancia. Esto resulta interesante porque la práctica de la constante rotación y movilidad, tanto de las personas que ocupan altos cargos públicos como de los mismos organismos de gobierno que son creados, renombrados y destruidos constantemente, parece ser una característica del régimen venezolano actual.

Por otra parte, Gentile agrega los temas de la sacralización de la política y el del carácter necesariamente palingenésico de la ideología, mientras que Lefort desnuda la lógica totalitaria en el mundo simbólico de las representaciones; desde este punto de partida, el totalitarismo es la sustitución del espacio vacío por la unidad del pueblo y del líder.

¿Qué lecciones podemos extraer de estas teorizaciones? ¿De qué manera nos pueden orientar para observar el totalitarismo, no ya como semántica (eso nos llevaría por otros derroteros) sino desde un punto de vista socioestructural?

Lo primero que llama la atención es la selectividad con la que se construye la categoría científica de totalitarismo. Se eligen características comunes (más que todo entre el nazismo y el comunismo, aunque la tendencia ha sido a generalizarlas aún más de modo que se puedan incluir otros regímenes) y destacadas de los casos históricos más representativos. Todas ellas, sin duda, se refieren a variables importantes dentro del sistema político; sobre todo un sistema político que se pre-concibe organizado democráticamente. Por tanto, la explicación se desplaza a la teoría de la democracia, la cual debe dar cuenta de cómo funciona un sistema político plural: cuál es el rol de los partidos políticos, las garantías a la libertad individual, las formas de representación, la libertad de prensa, la diferenciación Estado/ sociedad, etc. Teniendo en cuenta cómo funciona correctamente un sistema democrático pueden reconocerse así sus desviaciones; y aquí el totalitarismo parece ocupar el lugar del opuesto perfecto del sistema democrático. Tendríamos entonces una forma de dos lados.

El problema con esta distinción es que siempre se puede observar quien la traza y con ello se relativiza y pierde su potencial analítico, pues es denunciada como mera ideología (v.g. Zizek 2001). El otro problema que surge del método de clasificar con rigor las características destacadas del fenómeno es el siguiente: en la medida en que el concepto de totalitarismo no es sólo un concepto científico sino también político, y en tanto éste se ha venido cargando (sobre todo a partir de 1942 cuando se hace claro que no es posible una victoria alemana) de connotaciones 
negativas, aquellos regímenes que en un principio quisieron imitarles, se vieron en la necesidad de marcar distancias frente a ellos (tanto en sus discursos, como moderando ciertas prácticas); entretanto, el concepto de democracia se convirtió en una suerte de requisito de aceptación en el establishment internacional y todo Estado que quisiese ser reconocido, ingresar en el sistema ONU y tener acceso a los créditos del Banco Mundial y el apoyo del Fondo Monetario Internacional, tenía que por lo menos disimular su carácter no democrático; además, definirse como comunista (en tanto la URSS, la China maoísta y la Cuba de Fidel se mostraban como modelos "esperanzadores") permitía disimular formas de dominación totalitarias, sostenidas por el prestigio de la dialéctica revolucionaria. Este escenario tan complejo logró varias cosas: primero, que alternativamente se acusase o se excusase a los países comunistas de ejercer prácticas totalitarias o de ser totalitarismos tout court; y segundo, que en la medida que el comunismo se desacreditaba, con el corolario de la caída de la URSS, los Estados adoptasen fachadas democráticas (constituciones, elecciones, sistemas representativos, cierta libertad de prensa, etc.) para adaptarse a las nuevas relaciones de poder bajo un nuevo orden internacional.

De allí que hoy en día la ciencia política tenga que enfrentarse con el problema teórico de los regímenes híbridos (Levitsky \& Way 2010). Si miramos bien, la evolución del poder en las últimas décadas apunta a la producción de nuevas variaciones en la organización e instrumentalización del poder, cuya ventaja radica en su inmunización frente a las disensiones internas (como las protestas y la organización de la sociedad civil) y a las presiones internacionales, a través de la adopción de camuflajes democráticos. Esa tendencia que los teóricos políticos señalan con cierto orgullo, refiriéndose al incremento de los gobiernos democráticos alrededor del globo, bien podría ser un espejismo.

La dificultad es que las categorías de análisis empleadas se generalizaron a partir de una situación histórica muy concreta; no es que no se haya comprendido tal situación, sería absurdo afirmarlo, mucho se habló de los efectos de la sociedad de masas, de la irrupción de la sociedad de clases, de la racionalidad instrumental y sus efectos alienantes, de las psicopatologías del hombre autoritario, de la modernidad, etc. El problema es que se ha comprendido el poder como forma de gobierno plasmada en la estatalidad, y concebimos esta forma de gobierno como algo que es y deja de ser, que se transforma de una forma a otra, y nos hemos quedado sin herramientas para explicarnos el porqué 
de esas transformaciones; sólo nos limitamos a confeccionar descripciones e interpretaciones ex post y a reciclar o inventar categorías ad hoc para describir los nuevos fenómenos -así se ha hablado de estatocracia, logocracia, totalitarismo suave, postotalitarismo, etc. Justamente ese enfoque naturalista-fenoménico, es el que logra que las categorías de análisis sucumban ante la historia, tan rápidamente como sus objetos de estudio.

No queremos decir que lo que proponemos de alguna manera podría abstraerse de la historicidad del ser allí; tal cosa sería una tontería. Pero sí queremos sugerir que es posible emplear categorías de análisis más abstractas, con mejores rendimientos, y que justamente tengan en cuenta la historicidad de los fenómenos que describen. El poder debe comprenderse en su evolución: produce variaciones, las pone a prueba, éstas son seleccionadas y re-estabilizadas; experimentos que fueron exitosos durante algún tiempo deben reinventarse; las condiciones cambian, tanto dentro del sistema como en la complejidad inasible de su entorno. Construir una teoría política que no tenga en cuenta estas condiciones dejaría siempre nuestras capacidades analíticas al rezago.

Tomando en cuenta estas reflexiones, de todas las alternativas examinadas es la de Claude Lefort aquella que nos puede ofrecer un punto de partida interesante. Si lo examinamos con detalle, veremos que Lefort está hablando de la constitución paradójica del sistema funcional para la política. Empecemos entonces por aquí.

2. EL SISTEMA POLÍTICO, SU CONSTITUCIÓN PARADÓJICA Y EL TOTALITARISMO COMO FORMA DE AUTODESCRIPCIÓN TAUTOLÓGICA

En una sociedad funcionalmente diferenciada ya no existe ningún sistema, ni ningún "lugar" dentro de ningún sistema, desde el cual la sociedad pueda representarse en su unidad. Sólo quedan las autodescripciones de cada sistema funcional; la sociedad misma es irrepresentable. El sistema político, incluso, dada su complejidad y su indeterminación autogenerada, no puede ser representado en su unidad sino a través de un valor imaginario, a través de autodescripciones (Luhmann 1996).

Las autodescripciones ocultan la paradoja inherente a cada sistema, la unidad de su diferencia. En el caso del sistema político se suele acudir a la autodescripción del Estado y de la democracia; la primera representa la unidad del sistema, mientras que la segunda establece una diferencia, a saber, aquella entre gobierno y oposición. La semántica democrática -que 
ha evolucionado dejando múltiples huellas en el sistema social- se ha encargado, a partir de su formulación decimonónica, de fijar los términos en los que se presenta actualmente la autodescripción democrática del sistema. Se trata, en términos simples, del autogobierno del pueblo. Pero, ¿cómo puede el pueblo gobernarse a sí mismo? La respuesta que ofreció la ciencia política ilustrada, sobre todo los federalistas norteamericanos, fue la representación.

No obstante, la democracia parlamentaria que se había erigido durante el siglo XIX, comienza el siglo XX enfrentada a múltiples competidores ideológicos (autodescripciones alternativas): comunismo, socialismo, anarquismo, anarcosindicalismo, nacionalsindicalismo, nacionalsocialismo, entre otros. Había caído en descrédito el sistema parlamentario: se quería sufragio universal; los socialistas se decepcionaron de la claudicación de sus líderes ante el sistema capitalista al haberse integrado en el sistema parlamentario; los comunistas se entusiasmaban con la revolución rusa y estimaban cercano el fin del capitalismo; y había quienes recogían descontento de todas partes para echarlo todo al suelo. De modo que, de manera simplificada, la crítica de estas ideologías consistía en señalar que la representación era una farsa; que sencillamente se trataba de un artilugio para que una oligarquía dominase sobre las mayorías. En consecuencia, muchas de estas ideologías prometían una verdadera democracia, donde el pueblo se gobernase a sí mismo.

Aquí tenemos las dos clases de autodescripción descritas por Luhmann (1996), la natural y la artificial. Las autodescripciones naturales son tautológicas, ya que parten del hecho de que no existe contradicción alguna en la autorreferencia del sistema; recurren a identidades que se igualan unas con otras soportándose en cierto inmanentismo metafísico (Voegelin 2006). Este es el tipo de autodescripción que predominaba en las semánticas que criticaban a la democracia parlamentaria. Las autodescripciones artificiales por su parte son paradójicas, pues denuncian la existencia de una contradicción y a continuación sugieren algo para superarlas. Así, la teoría de la democracia moderna parte de que no es posible, prácticamente, que el pueblo de un país se gobierne por sí mismo al mismo tiempo, por lo que el pueblo debe elegir representantes que ejerzan los cargos públicos en defensa de los intereses comunes. Desde entonces, los problemas con esta autodescripción han estado en el señalamiento de aquellos casos en los que los representantes no representan al pueblo. De allí que, en momentos de efervescencia, el 
puente entre un tipo de autodescripción y otro esté tendido -a lo que habría que añadir la redundancia acumulada con las experiencias del siglo $X X$ que refuerzan tendencias tanto en una dirección como en otra.

En el caso que nos interesa, el de la revolución bolivariana, encontramos algunos paralelismos interesantes. El discurso político que encumbra a Hugo Chávez Frías a la presidencia de la República de Venezuela, se basaba en una ácida crítica a los partidos políticos (la partidocracia) y a la democracia representativa. La Constitución de 1999 estableció que desde entonces Venezuela tenía como forma de gobierno una democracia participativa y protagónica.

Desde muy temprano el chavismo manejó un discurso regeneracionista o palingenésico: se buscaba refundar la república, y con el tiempo (2005-2007) este proyecto va adquiriendo la forma del "socialismo del siglo XXI", un programa político que propugnaba la construcción de la vía venezolana al socialismo, transformando al Estado y creando al hombre nuevo. El socialismo del siglo XXI, aún examinado superficialmente, salta a la vista como una forma de autodescripción tautológica.

Más allá del hecho, de que se propone alcanzar una verdadera democracia, resulta revelador el empleo en el discurso de conceptos que se convierten en equivalentes; de sustantivos que comulgan en Uno. En los discursos de Chávez es común encontrar esas identificaciones (ver Chávez Frías 2009: 13, 271-272). Una de las identificaciones más notables se produce al morir Chávez en 2012, cuando se acuñan los eslóganes "Chávez somos todos" y "Yo soy Chávez". Todos estos son ejemplos de autodescripciones tautológicas: el chavismo apela a una unidad metafísica, el pueblo, y a un conjunto de principios morales y revolucionarios que por necesidad histórica habrán de efectuar la segunda emancipación del pueblo venezolano.

No hay que perder de vista que una de las características del chavismo es que carece de lo que los autores estudiados arriba han llamado una ideología estructurada. Chávez configuró su discurso tomando múltiples elementos semánticos, significantes vacíos (Laclau y Mouffe 2006), y los fue amalgamando con trazos del discurso republicano ético-estético-patético de nuestra tradición histórica (Castro Leiva, 2005). En igual sentido, ha desplazado el eje de gravedad de su discurso (los enemigos como el puntofijismo, el golpismo y el imperialismo y sus respuestas, la democracia participativa, la guerra asimétrica y el Estado comunal) en función de la situación político-estratégica. 
Estos cambios de estrategia discursiva suelen ser atribuidos a la capacidad política e ingenio del gran líder, cuya valía le permitió al movimiento chavista superar situaciones bastante delicadas, como aquellas de los años 2002-2004. No obstante, estas atribuciones esconden de nuevo la mitificación del "Comandante", quien encarna la voluntad popular, se hace Uno con la sociedad y se erige como paladín del pueblo frente a sus enemigos.

3. LA REPRODUCCIÓN AUTOPOIÉTICA BAJO UN PROGRAMA TOTALITARIO O LA COMUNICACIÓN POLÍTICA TOTALITARIA

La reproducción autopoiética depende de la redundancia y de la capacidad de enlace; la primera es cubierta por las observaciones y descripciones, mientras que la segunda se remite a la autopoiesis misma (Luhmann 1998a). La capacidad de enlace depende de los horizontes de sentido que, como diferencia entre acciones y vivencias actuales y potenciales, tiende puentes de un estado del sistema a otro. En consecuencia, la reproducción de la comunicación política depende de la recursividad de la decisión, es decir, de la manera en que decisiones vinculantes colectivas ya tomadas dan lugar a otras y así sucesivamente. Sabido es que el riesgo de la decisión presente compromete las decisiones futuras, las que tienen que lidiar con los efectos inesperados de las decisiones pasadas. Hasta aquí ninguna novedad. La cuestión es si un programa político basado en autodescripciones tautológicas puede afectar la reproducción autopoiética y de qué forma.

Hay indicios en la sociología política de Luhmann de que en efecto es así. El autor sostiene que en aquellos casos en los que la toma de decisiones está demasiado centralizada en pequeños grupos de interacción compitiendo entre sí y, por ende, las premisas de sus entendimientos se fijan de forma demasiado concreta, se corre el riesgo de que el sistema pierda sensibilidad frente a su entorno y se reduzca consecuentemente la prestación selectiva del mismo. Se politizan el resto de los sistemas sociales, reduciéndose a funciones secundarias ante la ausencia de alternativas. La producción, la administración y la investigación se reducen a la mera ejecución de programas, mientras que el arte, la literatura, la filosofía y las ciencias sociales se minimizan a funciones cosméticas (Luhmann 2007a: 43). Pero ¿cómo y por qué puede ocurrir esto que señala Luhmann? 
La comunicación política totalitaria se caracteriza por la reducción del horizonte de sentido de la decisión política, cuyas consecuencias son el empobrecimiento de las alternativas y la radicalización política, pues toda contingencia será desplazada al entorno, y en la medida en que estas inestabilidades estructurales vuelvan a repercutir sobre el sistema político, se buscará someter organizacionalmente la fuente de inestabilidades o aniquilarla físicamente.

Esta reducción se produce a partir de una configuración particular entre la codificación y la programación del sistema -la cual depende a su vez de la inflación del poder- que la cataliza. Es por esto que reviste especial importancia para comprender los cambios operados bajo un programa totalitario, examinar la estructura del poder como medio de consecución.

\section{EL PODER TOTALITARIO}

Aquello que denominamos totalitarismo designa una serie de procesos diversos y que se condicionan entre sí. Para comprender a cabalidad el fenómeno es menester entonces identificar los cambios estructurales dentro del medio de consecución poder. Partimos del principio de que el poder en su evolución ha logrado adquirir gran complejidad, pues ha adquirido las estructuras del código, la autoubicación del código en uno de sus valores, la reflexividad procesual, la inflación y deflación, los símbolos simbióticos, la observación de primer y segundo orden, los programas, la simbolización de la inclusión de lo excluido y la formación de sistemas. Examinemos pues algunos de estos aspectos que consideramos especialmente importantes.

\subsection{CODIFICACIÓN}

Históricamente, variantes de procesos de totalitarización de la comunicación política como los de la URSS, la Alemania nazi, la Italia fascista, la España franquista, la China maoísta, la Cuba castrista, la República jemer, el Japón imperial y Corea del Norte, han emergido en formaciones sociales en las cuales las formas vigentes de organización del poder no han logrado alcanzar la diferenciación de la codificación secundaria gobierno/oposición, o bien no han logrado re-estabilizarla. Esto significa que la comunicación política se reproduce fundamentalmente orientándose por el código primario gobernante/ gobernado. 
Pero en una sociedad funcionalmente diferenciada y dentro de un sistema funcional de la política cada vez más complejo, esta codificación primaria es incapaz de reducir adecuadamente la complejidad del entorno y la propia complejidad autogenerada. De manera que se produce una diferencia de gradientes de complejidad entre un entorno interno hipercomplejo y una forma hipocompleja de organización del poder. Tanto en el caso de Estados como Alemania o Italia, que sufrieron procesos de incremento de la complejidad de su estructura de poder (lo que han llamado la implementación de sistemas parlamentarios), como en donde no se habían presentado estos procesos, como en Rusia, el aumento de las posibilidades en el enlace de las comunicaciones políticas producía grandes inestabilidades que sólo pudieron reducirse acortando la circulación del medio a través de autodescripciones tautológicas. De esta manera, las contingencias no se desplazaban al lado reflexivo del código, sino que se exteriorizaban al entorno interno del sistema político (imperialismo o diatribas nacionalistas) o al sistema social (el capitalismo o el antisemitismo). El lado reflexivo del código se convertía en un espejo del lado positivo, reflejando sencillamente las determinaciones de sentido que se actualizaban. Esto se alcanzaba introduciendo identidades como formas de representación del sistema.

Toda incertidumbre surgida a partir del reflejo de la circulación del medio era canalizada mediante la introducción de la diferencia amigo/ enemigo de manera ortogonal al código principal. Con ayuda de esta codificación (fungiendo como codificación secundaria), toda contingencia negativa es atribuida al enemigo, al tiempo que toda ocurrencia positiva es valorada como amistosa. Se tenían así gobernantes amigos y gobernantes enemigos; y los gobernados amigos eran calificados como fieles y leales seguidores, mientras que había que encargarse de los gobernados enemigos. De esta manera, se duplica la información y de igual modo se encarrila la comunicación política y se ponen a disposición determinadas formas de instrumentalización del poder (volveremos sobre esto en el punto 4.4.3); la coligación de grupos, la movilización, la formación de consensos, la adquisición de apoyos, la configuración del discurso político, la confección de identidades, todos estos factores son condicionados por este código.

En este escenario, el caso de Venezuela parece anómalo, pues el código gobierno/ oposición se había logrado estabilizar en el periodo de 1958 hasta 1998, y aún hoy en día no puede decirse que el código no se encuentre operativo. Aunque, en efecto, hay que conceder que el código 
secundario en el Estado revolucionario y bolivariano ha experimentado alteraciones. ¿En qué consisten tales alteraciones?

En este caso, volvemos a encontrar la intromisión del código amigo/ enemigo, pero esta vez engarzado con la codificación secundaria gobierno/ oposición. En vez de tratar con gobernantes amigos o enemigos, lo que indica una relación patrimonial entre el gobernante y su Estado, se trata ahora de la relación entre gobiernos amigos y gobiernos enemigos. Esta nomenclatura da cuenta de la diferenciación cargo/ persona, por tanto, quien gobierna lo hace temporalmente y la enemistad se dirige hacia el gobierno -aunque naturalmente también se puede personalizar. La posibilidad de una oposición amiga da cuenta, por un lado, de la complejidad del espectro político, pero por otro, y de manera más plausible bajo un programa totalitario, la oposición amiga designa las expectativas que el gobierno dirige hacia su oposición: una oposición dócil que convalida la dominación totalitaria, al tiempo que mantiene las apariencias democráticas. De esta manera, la comunicación política del gobierno establece una distinción entre una oposición buena (leal) y una oposición mala (desleal), la cual se emplea como excusa para aplicar medidas coercitivas hacia la oposición desleal, restringiendo con esto su campo de acción. Veamos esto con mayor concreción.

A partir de 2002, la oposición liderada por organizaciones de la llamada "sociedad civil" y los medios de masas ejercieron una férrea resistencia frente a las medidas consideradas arbitrarias y comunistoides del gobierno de Hugo Chávez. Movilizaron los recursos que tenían a su disposición: el control de canales televisivos de amplia difusión nacional y la beligerancia del sector sindical federado. La oposición se vale de los mecanismos de contrapoder en un sistema político complejo, donde el ejercicio del poder está establecido con base en competencias jurídicas. La estrategia de la oposición consistía en: a) denunciar el carácter comunista del régimen y así deslegitimarlo (recurriendo al tradicional lugar común del miedo al comunismo) y b) producir una huelga general con apoyo de la sociedad civil que hiciera claudicar al gobierno (Martínez Meucci 2012: 45-78).

Sin embargo, el gobierno no estaba dispuesto a claudicar; disponía de suficientes reservas internacionales para contrarrestar el paro general y empleó simultáneamente una estrategia propagandística que volvió a las masas en contra de los gremios y factores de la "sociedad civil". La escalada del conflicto que dio paso a la mediación internacional no logró otra cosa que darle tiempo al gobierno para ganar la popularidad perdida; 
el golpe de abril de 2002 es empleado también por el aparato propagandístico del gobierno en contra de la oposición (aunque su uso se hará más intenso una vez terminada la mediación internacional). La estrategia de apaciguamiento, diseñada bajo los paradigmas tradicionales de la negociación por parte de la OEA y el Centro Carter, hizo perder de vista que cuando se trata con un gobierno revolucionario, toda concesión es temporal, ya que no existe conciliación posible con el enemigo (Martínez Meucci 2012: 435-440). De esta manera, el gobierno salió favorecido del conflicto y la oposición debilitada. Entonces, la oposición abogó por una estrategia más radical: no participar en las elecciones parlamentarias y de esta manera deslegitimar al régimen, pues estimaban que la alta abstención pondría en entredicho el talante democrático del régimen. Sin embargo, lo que lograron fue entregarle al chavismo el control sobre el legislativo. Siguió una estrategia de protestas generalizadas (llamadas guarimbas) y de constantes marchas que el gobierno supo contrarrestar con contramarchas y empleando la propaganda para desacreditar a los guarimberos.

En este escenario, en el cual el chavismo poseía todos los cargos de poder importantes del Estado (una estructura de poder que, aunque la constitución prescriba como descentralizada y federal, es altamente centralizada), las posibilidades de la oposición oscilaban entre la insurrección y la participación electoral. Al fallar la primera, decidieron optar por la segunda a partir de 2006; en 2008 se consolida una coalición de partidos políticos opositores llamada Mesa de la Unidad Democrática (MUD) -ahora el protagonismo de la oposición política lo tomarían los partidos políticos-, con lo cual la oposición crece políticamente; y crece porque naturalmente al participar en las elecciones puede acumular puntos en ese juego de suma variable del poder que permiten las elecciones; de esta manera, la cuantificación de votos permitía medir músculo entre los partidos de la oposición y trazar estadísticamente proyecciones de crecimiento electoral.

No obstante, contando con el apoyo de las mayorías embelesadas por las misiones y por los distintos mecanismos de subsidio al consumo, el chavismo sacaba una ventaja importante frente a la oposición. Aunado a ello, el control del Consejo Nacional Electoral (CNE) y la aplicación de las estrategias del voto gregario y el voto comprado, si bien no impedía el crecimiento electoral de la oposición, no le dejaba superar cierto umbral; un margen cómodo que le permitía al chavismo gobernar y hacer alarde de su talante democrático. 
Es este escenario el que decimos codificado por el cruce de los códigos gobierno/ oposición y amigo/ enemigo. La estrategia propagandística del gobierno buscaba descalificar todo potencial avance opositor en la opinión pública y en el campo electoral, asociándolos con el golpe de abril (el cual se convirtió en un acontecimiento-trauma para la oposición y un acontecimiento-símbolo para el gobierno). Al mismo tiempo, se expresaba retóricamente en los discursos públicos el deseo del gobierno de contar con una buena oposición que respetara los resultados electorales sin cantar fraude y que se atuviese al juego "democrático". Es así como a partir de la diferencia entre una oposición amistosa y una oposición no amigable se pudo enclaustrar a la oposición entre alternativas cada vez más estrechas: participar electoralmente significaba legitimar al sistema, aunque prometía vagamente crecimiento electoral (es decir, ser capaz de medir el volumen de poder a través de los votos); mientras que rebelarse contra el sistema podría desenmascararlo, aunque los costos políticos que ello tendría serían sumamente altos en caso de fracaso (el problema es que el éxito de tal empresa no se mide de la misma manera, en este caso se trata de un juego suma-cero, o se triunfa o se fracasa, mientras que en el juego suma-variable de las elecciones hasta perdiendo se gana) (Álvarez 2013).

Otro factor a tener en cuenta en una forma de organización del poder más compleja, es la reintroducción del código dentro de sí. Este proceso inicia en Venezuela con la promulgación de la Ley de Descentralización de 1989. De esta forma, se abren nuevos espacios para la competencia política, con lo que el sistema político adquiere más complejidad. La sofisticación de la escena política consiste, como decimos, en la reintroducción del código gobierno/ oposición dentro de sí. En este sentido, dado que múltiples cargos de elección popular pueden ser ocupados por distintos partidos políticos, se generan relaciones más complejas entre el gobierno y la oposición. Así pues, el partido que controle el ejecutivo puede llamarse gobierno, mientras el resto son de oposición; pero en tanto los partidos que no son de gobierno puedan controlar alcaldías y gobernaciones, son también gobierno, aunque sean "de oposición". De modo pues, que se puede ser gobierno y oposición simultáneamente. ¿Qué consecuencias trae esto para el sistema político?

Lo decisivo con la reintroducción del código es la posibilidad de observar las alternativas, es decir, la oposición como alternativa puede ponerse a prueba y no queda como algo indeterminado. Al ocupar alcaldías y gobernaciones, los partidos de oposición pueden dar pruebas 
de que son capaces de asumir las tareas de gobierno, pero, así como tienen esa posibilidad, también pueden desacreditarse o volverse impopulares antes de llegar al gobierno; con ello se configura (aunque no siempre y no necesariamente) un horizonte político pobre en alternativas, que induce a la apatía y a la devaluación del poder como medio. El que el gobierno sea también oposición le permite no ser el único blanco de las críticas, sino que también le permite formular críticas y hacer comparaciones.

El que los partidos políticos opositores se hayan opacado como alternativa de gobierno ha ocurrido, en parte y en un principio, por la propia desorientación de los partidos políticos de la oposición, al haber sufrido un proceso de reorganización y de renovación generacional tras el descalabro sufrido en 1998 con el triunfo de Chávez; pero sobre todo, y desde 2006 hasta hoy día, por el cercamiento presupuestario y el bypass administrativo impuesto por el gobierno en circunscripciones importantes ganadas por la oposición (como fue el caso de la Alcaldía Mayor ganada por Ledezma en 2008 y también ha ocurrido más recientemente con la Gobernación de Miranda dirigida por el opositor Henrique Capriles). De esta forma, el gobierno de oposición, en las circunscripciones ganadas, se encuentra presupuestariamente atado de manos y no puede competir contra todos los recursos del gobierno; esta labor es complementada por la propaganda oficialista que no pierde de vista ninguna de las dificultades y fracasos que enfrentan estos partidos de oposición.

Es así como Venezuela tiene una oposición política y no la tiene; es así como se la ha hecho prisionera de sus propios dilemas y como el gobierno se ha permitido afirmar su carácter democrático, refrendado por una comunidad internacional que sólo atiende a los criterios formales y tradicionales -al menos hasta 2012.

\subsection{PROGRAMA}

En el conjunto de procesos que se desencadenan en el sistema político y que denominamos totalitarismo, concedemos gran importancia a los programas. Su función, como es sabido, consiste en establecer las condiciones bajo las cuales operará el código, es decir, fija la manera en la que se realizan las atribuciones de un lado al otro del código (Luhmann 2008).

Hemos establecido una relación entre el programa y la forma de autodescripción. Nos explicaremos. Pueden existir autodescripciones que 
no sean a su vez programas, pero las formas de autodescripciones tautológicas suelen convertirse en programas. Para ser exactos, el totalitarismo hace coincidir programa, autoobservaciones y autodescripción. Luhmann (1998a: 406) fija la diferencia entre autodescripción y autoobservación, en que la primera produce artefactos semánticos que sirven para la referencia de otras comunicaciones y que son capaces de indicar la unidad del sistema. En este sentido sugerimos emplear como apoyo teórico los estudios cognitivos sobre la memoria (Ruiz-Vargas 2002); de esta manera equiparamos las observaciones con la memoria episódica, mientras que las descripciones las hacemos equivaler con la memoria semántica (Blanco 2013: 132-138). En consecuencia, las observaciones son operaciones que producen acontecimientos-símbolo, cuya carga de sentido generalizado se emplea para orientar la reproducción autopoiética; mientras que las descripciones requieren una elaboración basada en la redundancia generada por las huellas de memoria que dejan los sistemas sociales (símbolos, jeroglifos, libros, periódicos, archivos, etc.). Ambas se refuerzan naturalmente entre sí.

Volviendo al caso del totalitarismo, el programa totalitario caracterizado por sus rasgos revolucionarios y palingenésicos- se apoya sobre una tradición de discurso que desparadojiza al sistema (autodescripción), a la vez que va reforzando su reproducción, construyendo acontecimientos simbólicos, protagonizados por héroes y villanos (autoobservaciones). El chavismo consistió desde sus inicios en un programa revolucionario: se proponía la refundación de la república. En la medida en que fue venciendo las resistencias, fue tomando forma el proyecto del socialismo del siglo XXI; aunque en cierto modo el chavismo siempre ha sido un programa ecléctico (naturalmente con claras simpatías hacia la izquierda): tomando del marxismo, del socialismo, del bolivarianismo, del republicanismo de la tradición histórica venezolana, del cristianismo e incluso de algunas "religiones populares".

En cuanto a las autoobservaciones, el chavismo se ha hecho del imaginario de la izquierda revolucionaria e insurgente, la cual llevó a cabo la guerra de guerrillas en la década de los 60. Esto le ha permitido fabricar una narrativa histórica de lucha por la emancipación de un pueblo históricamente siempre traicionado. Los acontecimientos simbólicos dentro de la narrativa chavista han sido: el Caracazo, el 27 de febrero de 1989 (masivas protestas que expresaron un descontento generalizado con la precariedad de las condiciones de vida en el país); el 4 de febrero de 1992 (día en que se efectúa una intentona golpista contra el gobierno de 
Carlos Andrés Pérez); y el 13 de abril de 2002 (día en que Chávez es rescatado de sus captores por una operación comando y restituido al poder).

En lo que a su función orientadora de la adscripción del código se refiere, el programa revolucionario ha configurado la escena política: por un lado, están los escuálidos, aquellos pity-yankees traidores a la patria; del otro lado están los revolucionarios, fieles patriotas que luchan por la redención del país. Todo acontecimiento atraviesa este filtro comunicativo y ello hasta el punto del absurdo: tanto así, como que hay agujeros contrarrevolucionarios en el asfalto, como reptiles saboteadores del sistema eléctrico o técnicas misteriosas a través de las cuales los EEUU "inocularon" el cáncer al presidente Chávez.

\subsection{OBSERVACIÓN DE SEGUNDO ORDEN}

La forma que adopta la observación de segundo orden en la adquisición de complejidad estructural del medio de consecución poder es la opinión pública. Los comunicólogos suelen distinguir entre la opinión pública y el espacio público; por lo primero entienden lo que la gente verdaderamente piensa, mientras que por lo segundo entienden las posibilidades brindadas por medios como la imprenta, la radio, la televisión, Twitter, Facebook, entre otros. Según su punto de vista, Luhmann sólo se refiere al espacio público (Abreu Sojo 2009: 121).

Naturalmente las encuestas se encargan de producir comunicación en este sentido; hacen que "lo que la gente piensa" se traduzca en comunicación, es decir, que sea comentado, criticado y tenido en cuenta para la comunicación siguiente. Pero lo que ocurre en los sistemas psíquicos es sencillamente inasible, resulta demasiado complejo como para tenerlo seriamente en cuenta; además, la interpenetración entre sistemas psíquicos y sistemas sociales ha evolucionado hacia formas cada vez más cargadas de condicionantes, de modo que la coordinación es cada vez más difícil; por tanto, aunque sistemas sociales y sistemas psíquicos co-evolucionen conjuntamente, cada uno toma derroteros distintos pues cada cual construye su complejidad en base a tipos de operación distintos, a saber, la comunicación y la conciencia respectivamente. Como consecuencia de lo dicho, no interesa la individualidad sino desde la perspectiva de los sistemas sociales, es decir, no como socialización sino como inclusión (Luhmann 1993: 149-258). Y la inclusión no es un asunto que nos atañe aquí. 
Sin querer reducir el problema a lo semántico, cuya historia sin duda nos llevará al descubrimiento de otras dificultades, nos referiremos con opinión pública a las condiciones de la posibilidad de observar y ser observado en la política. Las prestaciones de los medios de difusión en este aspecto son irrefutables; indudablemente la opinión pública nace con la difusión de panfletos, libros, libelos y diarios gracias a la tecnología de la imprenta. Y hoy en día las prestaciones de los medios de masas y de los medios electrónicos han incrementado el rango de difusión de las comunicaciones y han dificultado su regulación. Sencillamente, las condiciones técnicas de los nuevos medios electrónicos se basan en redes de telecomunicaciones globales. Esto plantea grandes retos para los totalitarismos de este siglo.

La importancia del control sobre la opinión pública radica en que se pueden regular los temas que ingresan en la agenda pública. El monopolio sobre los temas de decisión es otro de los rasgos característicos de los totalitarismos. En este sentido, el Estado venezolano se ha destacado. Por un lado, ha logrado hacerse propietario de una buena parte de los medios de masas del país y también sujetar al resto a sus regulaciones e imposiciones -sobre esto volveremos más adelante. Por otro lado, en vista de que no puede controlar los medios electrónicos, pues los servidores y las compañías que prestan los servicios se encuentran fuera de la jurisdicción del país, han tomado la inteligente decisión de ocupar esos espacios, participando también en ellos. Así pues, antes de morir, Chávez se hizo abrir su cuenta en Twitter; Nicolás Maduro $\mathrm{y}$ otros personeros del gobierno le han secundado. Se habla informalmente del trabajo de laboratorios, es decir, de personas a sueldo que manipulan cuentas de Twitter y crean trending topics, apoyando la labor del gobierno.

De esta forma, el gobierno ha logrado imponer una importante hegemonía sobre los temas de decisión pública. A pesar de que en algunas ocasiones tal control ha demostrado sus grietas, como con el tema de la inseguridad desde 2012, el cual la oposición logró incluir en la agenda pública. Este estado de cosas retroalimenta la pobreza de alternativas en el enlace comunicativo del sistema, al tiempo que toda adversidad se exterioriza y sirve como impulso para "radicalizar la revolución"; es decir, toda falla significa que la revolución debe profundizarse, controlando cada vez mayores sectores del entorno social (entendiendo este control como la sujeción legal de organizaciones no políticas), mas no implica de ningún modo que la revolución sea el error. 


\subsection{INFLACIÓN}

Hablamos de inflación cuando el medio, en su circulación, supone mayor confianza de aquella que puede soportar. La inflación del medio puede llevar a la devaluación de sus símbolos, cuya consecuencia es, de nuevo, el empobrecimiento del horizonte de posibilidades para que la comunicación encuentre enlaces (Luhmann 1998b: 382-386). Esto significa que la revolución avanza como un proceso fatal e irreversible, presa de su propio desenfreno, pero también significa la pérdida de confianza en el poder, lo que adquiere la forma de la apatía o la resignación, desde donde puede llegar a pendular hasta el descontento abierto. Negación de la política y politización extrema son los extremos entre los cuales oscila la comunicación política cuando el poder sufre de inflación.

Observaremos este fenómeno inflacionario estudiando tres dimensiones esenciales del poder, a saber, su organización, su simbolización y su instrumentalización.

\subsubsection{ORGANIZACIÓN}

Como es bien sabido, los sistemas funcionales requieren de las organizaciones; $\mathrm{y}$, de la misma manera, algunos medios de consecución como el poder, no pueden prescindir de las prestaciones de este sistema social. Con el propósito de que sean estabilizadas las transmisiones de selecciones de complejidad reducida, bajo la condición del uso de la violencia física como alternativa que se desea evitar (Luhmann 2005a), las organizaciones cumplirán la tarea de simbolizar el monopolio de tales posibilidades en un marco territorial determinado. En este sentido, toda organización especializada en el empleo de la violencia es una forma de organización del poder. La extensión territorial y la complejidad del entorno social empujarán al refinamiento organizativo de estas estructuras, hasta el punto de que sus decisiones se enlazan recursivamente, creando una historia propia y valores propios (von Foerster 1993). De modo que el Estado moderno no es otra cosa que una variación evolutiva dentro las formas de organización del poder.

En sentido estricto, el Estado no es una organización, sino un acoplamiento entre varias organizaciones que se relacionan entre sí en términos de diferenciación de roles, jerarquía y jurisdicción territorial. Desde este punto de vista, las formas de organización del Estado moderno 
son muy variadas, algunas responden a modelos centralistas, otras a modelos federalistas y algunas incluso a modelos mixtos.

Luhmann ha estudiado este problema desde dos perspectivas entre las cuales existen grandes líneas de continuidad. En su etapa funcionalestructuralista alegaba que el sistema político desplegaba dentro de sí, dadas ciertas condiciones de construcción de complejidad, una diferenciación funcional. Por un lado, se desplegaba la función de la preparación del consenso para la toma de decisiones, es decir, se trataba de las condiciones para la presunción de disponibilidad del poder legítimo. Esta es la función de la política. Por otro lado, era necesaria la implementación o imposición de las decisiones políticas. Esta es la función de la administración. A esta diferenciación funcional solía acompañarle también una diferenciación estructural que obedecía a los programas de decisión característicos de cada uno: programas de fines para la política y programas condicionales para la administración. Posteriormente Luhmann (1997; 2000) introduce el trío: política, administración y público, describiendo con ello el funcionamiento del medio de consecución poder, basado en dobles ciclos, a saber, el ciclo del poder y el del contrapoder. Ya resulta inadecuado emplear la figura de la jerarquía para comprender el funcionamiento del poder, pues en la sociedad moderna éste opera en una circularidad. De parte del poder formal se disponen de competencias reguladas jurídicamente y tiene la capacidad de hacerse imponer en situaciones de conflicto, y de otra parte el ciclo informal del poder tiene su sustento en la sobrecarga de complejidad del sistema y suele imponerse en los casos regulares. Esta diferenciación interna obedece a la disponibilidad de mayores puntos de contacto interno, direcciones para la comunicación interna, que elevan la complejidad estructurada del sistema.

A estas consideraciones vale hacerle alguna que otra adición. Normalmente, cuando existe lo que en la teoría de las relaciones cívicomilitares se denomina "control civil", las Fuerzas Armadas son sólo otro componente dentro de la administración pública, el cual despliega sus competencias exclusivamente en el campo de la seguridad nacional. Ahora bien, esta no es la única configuración posible de los circuitos de poder (ciclos y contraciclos). Entender al poder organizado en su dimensión evolutiva entraña interrogarse por las particularidades históricas de los distintos Estados. En algunos las Fuerzas Armadas y la administración han podido evolucionar en sinergia, en otros los militares han jugado un rol político fundamental (pretorianismo) $\mathrm{y}$, finalmente, también existe aquel caso en el que la administración no se las tiene que 
ver con este elemento (caso de Costa Rica). Así pues, en aquellos casos en los que la evolución de la burocracia y de las Fuerzas Armadas les haya llevado a enfrentarse, tendríamos que añadir a las Fuerzas Armadas a la fórmula tripartita de Luhmann, pues su monopolio sobre la fuerza les hace jugar un rol fundamental en la generación de consensos y la imposición de decisiones.

Si bien la organización del poder en el ámbito de la administración y las Fuerzas Armadas es bastante evidente, también debemos observar la importancia del fenómeno organizativo en la política y el público. La política, aunque dependa fuertemente de los sistemas de interacción, realiza importantísimas prestaciones a la tecnificación del código cuando está organizada a través de los partidos políticos. Y el público, si bien suele estar atomizado, en formaciones sociales complejas puja por organizarse en organizaciones no gubernamentales (ONG), asociaciones vecinales, grupos de presión o lobbies, entre otros, es decir, aquello que suele denominarse "sociedad civil".

Frente a este escenario, el Estado totalitario de alguna manera responde ante el incremento de la complejidad organizativa del sistema. Éste acelera el crecimiento organizacional del Estado, no obstante, coarta la autonomía funcional de la política, la administración, el público y las Fuerzas Armadas.

En Venezuela el proceso de sujeción total del Estado comenzó muy poco después de la asunción del cargo por parte de Hugo Chávez, con el proceso constituyente que le permitió controlar buena parte del aparato estatal (Combellas 2007: 47-76). El conflicto con la sociedad civil tras pretender imponer 49 decretos-leyes en noviembre de 2001 se salda con el subyugamiento de la Confederación de Trabajadores de Venezuela y Petróleos de Venezuela y como resultado de la "Guerra de las Salas del TSJ" termina ganándose para sí al poder judicial. Aprovechando el tiempo que el Poder Electoral permite ganar al gobierno, poniendo cientos de objeciones para la convocatoria del Revocatorio, Chávez lanza un plan ambicioso de políticas públicas para atacar problemas de alto impacto social (las misiones), al tiempo que se crean estructuras paralelas a los ministerios (Martínez Meucci 2012).

En cuanto a las Fuerzas Armadas se refiere, el golpe de 2002 le permite a Chávez iniciar un proceso de purgamiento, en el cual se deshará de aquellos sectores opositores (muchos se declararon en desobediencia civil y protestaron en la Plaza Francia, con lo cual le facilitaron al gobierno la tarea) e institucionalistas, dejando solamente a los leales. Éstos son 
premiados con cargos públicos en distintos niveles de la administración (Guardia Rolando y Olivieri Pacheco 2005: 76-100). Ya desde el año 2000 Chávez empleaba las Fuerzas Armadas como un brazo político; con el Plan Bolívar 2000 echó mano de las mismas para llevar a cabo políticas públicas. Tras vencer a Manuel Rosales en diciembre en las elecciones presidenciales, propone una reforma constitucional (15 agosto de 2007), en la cual desarrolla una nueva doctrina militar bolivariana basada en la guerra asimétrica: las FANB jugarían un rol importante en la garantía de la soberanía nacional frente a cualquier ataque externo e interno. En septiembre propone también la formación de una milicia popular bolivariana (García Larralde 2008: 245-257). La creación de fuerzas paralelas como las milicias, y posteriormente la Guardia del Pueblo, le permitirá a Chávez obtener un dominio absoluto de las Fuerzas Armadas e impedir un levantamiento generalizado en las mismas, disponiendo de amplio margen de maniobra, repartiendo fuerzas entre elementos profesionales y civiles.

Teniendo la estructura de cargos del Estado a su merced, se cataliza el proceso de inflación organizacional del Estado venezolano.

Con la reforma de 2007 se propone la creación de un nuevo modelo de Estado y de sociedad basado en los lineamientos ideológicos del llamado "socialismo del siglo XXI"; se preveía la creación de un Estado comunal y con ello la reorganización del Estado teniendo como célula principal los Consejos Comunales. Aunque Chávez pierde el referéndum que habría de aprobar la reforma constitucional, impone unilateralmente las reformas sugeridas en el proyecto mediante facultades extraordinarias concedidas por el legislativo vía Ley Habilitante; desde entonces hasta 2012, cuando muere, Chávez se ocupó de la construcción de su Estado comunal, creando estructuras de bypass frente a las tradicionales alcaldías, municipios y gobernaciones.

Paralelamente al proceso señalado, se genera también un proceso de duplicación e infiltración organizacional de los distintos gremios y corporaciones de la sociedad civil. (García Larralde 2008: 538-542). Y a raíz del golpe de 2002 el chavismo inicia una ofensiva en contra de los medios de masas. Según el plan formulado por Andrés Izarra el gobierno debía ejercer una hegemonía comunicacional, con la excusa de que no volviese a ocurrir una situación en la que los "medios de comunicación privados" sirviesen a intereses particulares y extranjeros, ocultándole al país la verdad. Para 2008-2009, el Estado venezolano contaba con más de 400 medios de masas a su disposición, entre televisoras, radioemisoras y 
órganos de prensa (Oropeza 2009: 68). Desde 2013, el gobierno nacional inició una estrategia dirigida a adquirir medios de masas privados a través de testaferros, con lo cual, una vez adquirido el medio, reorientaban su línea editorial en una dirección favorable al gobierno.

No hay que pasar por alto que a la dimensión nacional le acompaña la dimensión internacional. Si el chavismo no hubiese construido un "sistema de alianzas", soportado en nuevas organizaciones internacionales (ALBA y UNASUR), habría carecido del éxito y del prestigio del que gozó -y naturalmente esto a su vez no habría sido posible sin las riquezas obtenidas por los altos precios del petróleo.

Como la legitimidad no es una cuestión meramente interna, los Estados autoritarios tienden a establecer relaciones de cooperación entre sí. Pueden intentar promover unilateralmente su modelo político (programa) y/ o tantear entre una estrategia basada en un modelo carismático y expansivo de legitimidad y otra basada en un modelo burocrático y defensivo (Hoffmann 2011) para lograr acomodarse en el orden internacional. En este caso, Chávez adoptó una política exterior expansiva basada en su carisma personal y buscó exportar su revolución bolivariana (y podría decirse que tuvo éxito en los casos de Ecuador y Bolivia); entretanto, el país redibujaba el esquema de sus aliados internacionales, acercándose a Estados forajidos como Irán, Bielorrusia y Libia y a otras potencias como China y Rusia (Romero 2006). Los autoritarismos suelen apoyarse mutuamente a través de modelos de cooperación basados en el aprendizaje (copiar estrategias exitosas al enfrentar situaciones similares), la emulación (imitación de otros Estados por razones normativas, de legitimidad y prestigio) y la socialización (proceso de aprendizaje complejo en el cual los actores redefinen identidades e intereses) (Erdmann et al. 2013).

En cuanto a la política internacional se refiere, el chavismo se anotó grandes éxitos, pues estos mecanismos de cooperación fueron amplificados por las organizaciones intergubernamentales; además las declaraciones de apoyo que emiten, las misiones de observación electoral y la discusión de asuntos regionales que promueven, generan apoyos políticos, granjean popularidad en la opinión pública internacional y confieren aceptación a los Estados no democráticos. 


\subsubsection{SiMBOLIZACIÓN}

Más allá del tema de la generalización simbólica, ya resuelto en una sociedad funcionalmente diferenciada, lo que nos interesa aquí son aquellos atajos comunicativos, aquellas representaciones de las que se reviste el poder para hacerse presente donde está ausente -o simplemente para representar su presencia. La comunicación del poder no transcurre únicamente bajo la forma de decisiones vinculantes colectivas; es un fenómeno multidimensional que abarca tanto lo semántico como lo semiótico. Ya hemos examinado brevemente las dimensiones semánticas al hablar de autodescripciones y programas, ahora resta echar un vistazo a lo simbólico y dar cuenta de cómo también en este ámbito se manifiesta la inflación del medio.

Es en la dimensión simbólica del poder donde se produce la redundancia social que engendra certidumbre, confianza, y en ocasiones, hasta fe. Estos símbolos representan la majestad de un cargo, un gran poder, una gran dignidad, honor, respeto, admiración, entre otros. Cuando un alto funcionario público pronuncia un discurso, hay mucho más ocurriendo simultáneamente que la acción lingüística que se está ejecutando; este discurso se pronuncia en un lugar determinado, generalmente decorado con banderas, insignias, retratos o pinturas; y más allá de lo que se esté diciendo, se encuentra latente la posibilidad de emplear la fuerza pública para hacer aceptar las decisiones que se tomen, está presente igualmente la pretensión de convencer, ocultar/ engañar, justificar, etc.

La producción simbólica en la política es un equivalente funcional a la persuasión por medio de la retórica, a la hora de lograr la aceptación de la comunicación política. Estamos hablando entonces de un dispositivo del cual dispone el poder, como medio de comunicación simbólicamente generalizado, para llevar a cabo su función. En tal sentido, la selectividad de los símbolos políticos motiva a correr el riesgo de dejarse influir por la contingencia y complejidad de la comunicación política. Ahora bien ¿qué ocurre con los símbolos en proceso político totalitario?

Con el propósito de crear una identidad entre el pueblo y el líder, los símbolos políticos bajo el totalitarismo no marcan una distancia entre las instancias del poder y el entorno, sino que la elaboración simbólica busca incluso apropiarse de elementos de raigambre popular, marcados por lo mítico-religioso. En este sentido, la revolución bolivariana ha convertido lo que Germán Carrera Damas (2003) llamó el culto a Bolívar 
por el pueblo en un nuevo culto a Bolívar para el pueblo (Salas de Lecuna 1987). En esta operación simbólica podrían yacer importantes razones de su arraigo popular.

Desde el punto de vista religioso, Bolívar ha sido una figura invocada por espiritistas y por los seguidores del culto a María Lionza1; en particular estos últimos tenían la creencia de que Bolívar reencarnaría en el año 2000 y que tendría 33 años (Martín 1983; Pollak-Eltz 2004). El chavismo ha manipulado siempre estas creencias populares, mezclando en su discurso referencias religiosas que cada culto o secta puede tomar e interpretar a su gusto, pero siempre en un sentido redentor; así, sin convertirse el chavismo en una religión, explota las creencias religiosas para movilizar el apoyo hacia el proyecto revolucionario bolivariano. De manera que uno puede observar murales por las calles de Caracas representando a Jesucristo, Bolívar y Chávez, dando forma a una santísima trinidad patria; Chávez coincide aquí con el Espíritu Santo, cuyos tiempos se supone que vivimos y cuyo mensaje redentor es indiscutible.

\subsubsection{INSTRUMENTALIZACIÓN}

Por instrumentalización entenderemos las formas en que se acopla el medio del poder $\mathrm{y}$ que le permiten circular. En general, esos acoplamientos rígidos obedecen a dos tipos, las sanciones positivas y las sanciones negativas. Las sanciones positivas implican la concesión de algún beneficio pecuniario o incluso alguna dádiva como premio por la obediencia, o bien se desenvuelven como una relación de intercambio de beneficios por apoyo político; mientras que las sanciones negativas consisten en el empleo de la violencia física. Las sanciones positivas funcionan a condición de que se realicen, movilizan apoyos, pero no generan legitimidad; las sanciones negativas, por su parte, funcionan en tanto y en cuanto no se apliquen (Luhmann 2000: 44-47; 2005b: 121-130).

Los modernos Estados suelen recurrir cada vez más a las sanciones positivas, lo que está relacionado con la inflación del poder y del dinero,

\footnotetext{
${ }^{1}$ La leyenda de María Lionza es una versión hispanizada y cristianizada de una antigua leyenda aborigen. Entre las distintas versiones que existen, se dice que entre los indios caquetíos o nívar creció una muchacha de extraordinaria belleza, hija de un cacique, quien fue tragada por una serpiente que habitaba en el pozo que a ella le gustaba visitar. Entonces, tras estallar la serpiente que la engulló, la mujer se convierte en la dueña del agua, protectora de los animales y de la naturaleza. A partir de allí se desarrolla una tradición de devoción hacia una Diosa de la naturaleza capaz de realizar sanaciones a los enfermos sin esperanza. Se trata de un culto sincrético que involucra el espiritismo y la adoración de diversas deidades. (Martín 1983: 110-156)
} 
pues los mecanismos que permiten la circulación del dinero dependen tanto de los Estados como de los Bancos y benefician tanto a unos como a los otros: la capacidad presupuestaria del Estado se agranda con los mecanismos financieros, con lo cual asume más tareas y responsabilidades, y los bancos u otras organizaciones financieras ponen a prueba nuevos mecanismos para hacer circular pagos, partiendo de los condicionantes impuestos por las regulaciones estatales.

La inflación del poder y del dinero es una tendencia estructural de la sociedad moderna, por tanto, en este punto no hay distinción entre los procesos políticos democratizadores y los desdemocratizadores. Aunque bien podría pensarse que el totalitarismo es una de las expresiones de esta tendencia inflacionaria, siendo la otra el megaestado liberal. ¿Cuáles son entonces las características particulares de los totalitarismos en esta dimensión?

En totalitarismos como el chavista las sanciones positivas juegan un papel fundamental, pues adquieren la forma de políticas clientelares dirigidas a garantizar la lealtad a cambio de algún bienestar material. Este fenómeno se observó en Europa del Este como lo detalló Milan Simecka (Rupnik 1991: 69) y ahora lo observamos también en la revolución bolivariana -con todo, es una tradición del rentismo populista venezolano. Además de las ya mencionadas misiones, las políticas del gobierno se han dirigido también a subsidiar el consumo a través del control cambiario (mediante asignación de cupos en divisas para compras por internet y viajes al exterior, en una relación en la cual el bolívar se sobrevalua con respecto al dólar). Estas políticas causaron serios déficits fiscales en el presupuesto estatal, sobre todo tras la onerosa campaña presidencial de 2012, en la cual Chávez derrota a Capriles. En diciembre de 2013, el presidente Maduro denunció una guerra económica que las clases privilegiadas llevaban en contra del país, tomando la resolución de regular precios e intervenir comercios que abusaran de los precios -medidas que han acabado agudizando la escasez.

A diferencia de un megaestado, en el Estado totalitario las sanciones positivas se emplean para comprar lealtad; las prestaciones no son consideradas deberes del Estado sino logros de la revolución arrebatados a la oligarquía, beneficios concedidos por el Supremo Comandante. En efecto, se trata de técnicas de poder difundidas en la cultura política latinoamericana, pero no por el hecho de su generalización ha de deducirse la propensión del continente hacia el totalitarismo. En cuanto a las sanciones negativas, a diferencia del megaestado, los totalitarismos se 
caracterizan por el uso arbitrario de la fuerza en diverso grado de malicia, desde el genocidio -en contextos en los que esta práctica encontró condiciones de posibilidad, como la guerra y el poco desarrollo del derecho internacional público- hasta la denominada "violencia psicológica". La tendencia a la violencia desenfrenada de los primeros experimentos totalitarios ha dado paso a estrategias más sutiles. En todo caso, la latencia de la violencia -e incluso la realización de algún acto de violencia criminal pero políticamente intencionado- constituye un rasgo definitorio del poder totalitario.

\section{CONCLUSIONES}

El totalitarismo resulta de la introducción de un programa político palingenésico que despliega una forma de autodescripción tautológica dentro del sistema político, con la consecuencia de que la codificación del poder es intersecada por la diferencia amigo/ enemigo, acortando los horizontes de alternativas de la comunicación política, radicalizando al movimiento revolucionario y empujándolo hacia un dominio organizacional cada vez mayor de su entorno (integrando sistemas organizacionales como parte de la organización unitaria y orgánica del poder) que en casos muy virulentos puede llevar a la experimentación de formas muy macabras de acabar con la individualidad del hombre (supresión del entorno psíquico).

La revolución bolivariana representa un ejemplo de totalitarización del poder con énfasis en las sanciones positivas. En su funcionamiento, al tomar el aparato estatal, el chavismo ha desencadenado un proceso inflacionario que ha reducido la autonomía funcional entre la política, la administración, el público y las FFAA. Sustituyendo la confianza sistémica por la confianza personal, consiguió reducir el espectro de alternativas en la reproducción autopoiética de las organizaciones de la sociedad civil infiltradas, en las cuales un conjunto de sistemas de contacto (o grupos) integrados por la lealtad de sus miembros a la revolución monopolizan la toma de decisiones; y cuando esto no fue posible, se echaba mano de las sanciones negativas, de la explotación del resentimiento (entendiendo los sentimientos como medio de comunicación, Baecker 2007: 220-221) y de la violencia para ejercer coerción sobre las organizaciones díscolas. Finalmente, el plan más ambicioso de reorganizar toda la sociedad a través del Estado comunal que comprendería a las familias, pasando por los consejos comunales y las comunas, las ciudades, hasta cubrir la totalidad de la sociedad, representa a cabalidad el tipo de proceso 
inflacionario del poder totalitario: la reducción de todo a una unidad orgánica.

Estas consideraciones nos obligan a abordar, aunque sea de pasada, el problema de cómo se legitiman los totalitarismos. La función de legitimación del poder político, la cual se da en las democracias a través de procesos de articulación de intereses y negociación de acuerdos -en donde los partidos políticos juegan un rol fundamental-, ocurre en los totalitarismos fundamentalmente a través de la organización para la propaganda (Arendt 2004: 447). No es tanto que la gente crea en lo que dice la propaganda, es que se convierte virtualmente en la única alternativa, la única interpretación. Que en el mundo contemporáneo no sea posible un dominio absoluto de los medios de masas, obliga a responder a las discrepancias entre lo presentado por la propaganda y las versiones alternativas (y que sólo por ser alternativas pueden volverse más verosímiles) con mayores dosis de mendacidad y cinismo. La política compite con los medios de masas en la duplicación de la realidad, echándole justamente en cara el prejuicio de que los medios de masas manipulan la información y que sólo los medios del Estado ofrecen la "verdad verdadera". La realidad se divide entonces en atención al código político, a saber, entre oficialistas y opositores. De esta manera, se crea una ficción de consenso dentro del bando gubernamental (reforzado con esquematismos del tipo que atribuyen la crítica a la traición, los fracasos o escándalos a la infiltración o al sabotaje, entre otros) que se encuentra en estado de guerra contra los despiadados opositores (pity-yankees, escuálidos, oligarcas, etc.). De esta forma, automáticamente todo punto desfavorable de la oposición es un punto a favor del gobierno; y todo ataque a la oposición es anotarse un punto. Así pues, expropiar, desahuciar, suspender inmunidades parlamentarias y acusar por delitos comunes a los políticos opositores, se convierten en estrategias corrientes para ganar popularidad, a la vez que se suponen populares.

En lo que se refiere a la administración, es decir, a la imposición de sanciones, el Estado venezolano compra votos a partir de la distribución selectivamente clasista de sanciones positivas. Paralelamente, la impersonalidad de la ley permite hacer obedecer decisiones controversiales o vejatorias de derechos subjetivos al hacerlas pasar por el tamiz de la rutina administrativa. Se trata de medidas altamente políticas, pero que al someterse a la administración se despolitizan porque su discusión debe desplazarse a otro lugar (el Parlamento, donde se supone que ya se aprobaron). Es como si la política totalitaria combinara 
politización y despolitización a la vez: politiza para polemizar y movilizar y despolitiza para hacer obedecer decisiones que resultan impuestas a los disidentes y opositores. Se invita retóricamente al debate, pero las leyes ya están aprobadas y los ministerios las están implementando.

Si bien es cierto que el Estado totalitario puede legitimarse a través de la normalidad rutinaria de la administración, la propia eficiencia de ésta puede convertirse en causal de deslegitimación. En este sentido, los fracasos de la administración a la hora de alcanzar los objetivos políticos deben ser ocultados por la propaganda; y cuando esto no sea posible, hay que achacarlo a los chivos expiatorios habituales (el imperialismo, el sabotaje, la guerra económica, acaparadores, bachaqueros, etc. -y ahora: los colombianos); y cuando esto no sea convincente, hay que inventar otros nuevos. Si aún esto no es suficiente, se apela a la falta de moralidad revolucionaria de los funcionarios públicos, lo cual puede servir de ocasión para una purga y/o un reacomodo de fuerzas dentro de las facciones del gobierno.

En la medida en que todo fracaso tiene su causa en el exterior, la exigencia de corrección de resultados obliga a tomar el control sobre esa fuente de alteración. De manera que todo chivo expiatorio será víctima de alguna medida punitiva, al tiempo que su ámbito de acción será sometido en la medida de lo posible a la intervención estatal (control estatal de la producción en las industrias básicas, fiscalización del comercio, control de precios, etc.). Toda falla exige un culpable, todo culpable se convierte en víctima y en la medida en que los problemas se tornen más graves, las medidas habrán de ser más severas. Es así como se radicaliza el totalitarismo hasta el punto que la individualidad misma es fuente de inestabilidad, haciéndose necesaria su aniquilación física -al menos en las formas más virulentas de totalitarismo, como lo fueron sus primeras cepas nacionalsocialismo, estalinismo, comunismo chino y jemer rojo, entre otros.

El poder totalitario tiene la característica de que juega al borde del risco: toma decisiones que no puede soportar si se llega a un conflicto, y por ende provoca el conflicto, pero siempre con la intención de que el otro no se atreva a jugárselo todo; es como un jugador que apuesta al todo o nada en cada jugada. Esa propensión deliberada al conflicto es riesgosa, pues en caso de que el otro decida responder al reto, el país caería fácilmente en una guerra civil. Pero como siempre se está dispuesto a reducirlo todo a la violencia y el Estado monopoliza los medios de su ejercicio (o si no lo hace efectivamente el Estado, por lo menos lo ejerce de 
manera compartida con el movimiento totalitario), el rival se amedrenta y acaba por ceder; resistirá, quizá, pero sólo de palabra; y eso poco importa cuando la comunicación política engendra dos léxicos, el del gobierno y el de la oposición, como si se tratase de dos lenguas diferentes. En tal contexto, no hay persuasión posible, quedando el poder como el único medio efectivo de inducir a la aceptación de la comunicación. La sanción se impone al tercero excluido como vivencia (una ley, un reglamento, una resolución, una medida de emergencia para el bienestar de la nación), al tiempo que el directamente afectado es desvinculado del resto, debiendo internalizar en su propia individualidad las penurias sufridas por causa de la violencia pública o privada (pero revolucionaria).

La resistencia pasa por revertir esta separación, es decir, por hacer comunes los sufrimientos particulares; mas ello sólo alcanza -dadas las condiciones- para atizar uno que otro movimiento de protesta que despierta el resquemor de los partidos políticos de oposición y la inquietud del gobierno. Pero en tanto los temas que esgrimen se agotan, gracias a la dinámica de los medios de masas que se apropian de los temas y entretanto la gente se cansa de las acciones de calle, el movimiento se desinfla y al final del día poco habrá cambiado. RM

\section{REFERENCIAS}

Abreu Sojo, I. (2009). Propaganda, marketing político, opinión pública y democracia en la realidad venezolana del presente. En M. Bisbal (Ed.), Hegemonía y control comunicacional (pp. 119-154). Caracas: Editorial Alfa.

Álvarez, A. (2013). La oposición venezolana y el autoritarismo electoral. En M. Bisbal (Coord. /Ed.), La política y sus tramas. Miradas desde la Venezuela del presente (pp. 231-235). Caracas: UCAB.

Arendt, H. (2004). Los orígenes del totalitarismo. Madrid: Taurus.

Aron, R. (1968). Democracy and Totalitarianism. London: Weidenfeld \& Nicolson.

Baecker, D. (2007). Form und Formen der Kommunikation. Frankfurt am Main: Suhrkamp.

Blanco, J.J. (2013). La reforma del gobierno y la reforma del individuo. Elementos de una teoría política de la emancipación (1808-1830). Saarbrücken: Dictus Publishing.

Carrera Damas, G. (2003). El culto a Bolívar. Caracas: Alfadil Editores.

Castro Leiva, L. (2005). Obras. Para pensar a Bolívar. Vol. I. Caracas: Fundación Polar/UCAB.

Chávez Frías, H. (2009). 2006 "Año de la participación y el poder popular". Selección de discursos del Presidente de la República Bolivariana de Venezuela Hugo Chávez Frías. Tomo VIII. Caracas: Ediciones de la Presidencia de la República. 
Combellas, R. (2007). El proceso constituyente y la Constitución de 1999. En G. Maihold (Ed.) Venezuela en retrospectiva. Los pasos hacia el régimen chavista (pp. 47-76). Madrid: Iberoamericana/Vervuert.

Erdmann G., Bank, A., B. Hoffmann, T. Richter. (2013). International Cooperation of Authoritarian Regimes: Toward a Conceptual Framework. GIGA Working Papers, No.229

Forti, S. (2008). El totalitarismo: trayectoria de una idea límite. Barcelona: Herder.

Friedrich C. y Brzezinski Z. (1976). Dictadura totalitaria y autocracia: Buenos Aires: Ediciones Libera.

García Larralde, H. (2008). El fascismo del siglo XXI. Caracas: Debate.

Gentile, E. (2002). El fascismo italiano. En J.A. Mellón, Orden, jerarquía y comunidad. Fascismos, dictaduras y postfascismos en la Europa contemporánea (pp. 77-102). Madrid: Tecnos.

Gentile, E. (2004). Fascism, Totalitarianism and Political Religion: Definitions and Critical Reflections on Criticism of an Interpretation. Totalitarian Movements and Political Religions, 5(3), 326-375.

Grieder, P. (2007). In Defense of Totalitarianism Theory as a Tool of Historical Scholarship. Totalitarian Movements and Political Religions, 8(3-4), 563-589.

Guardia Rolando I. y Olivieri Pacheco G. (2005). Estudio de las relaciones cívico militares en Venezuela desde el siglo XIX hasta nuestros días. Caracas: Centro Gumilla/ UCAB.

Hoffmann, B. (2011). The International Dimensions of Authoritarian Legitimation: The Impact of Regime Evolution. GIGA Working Papers, No. 182.

Laclau, E. y Mouffe, Ch. (2006). Hegemonía y estrategia socialista. Hacia una radicalización de la democracia. México: FCE.

Lefort, C. (1990). Democracia y advenimiento de un "lugar vacío". En C. Lefort., La invención democrática (pp. 187-194). Buenos Aires: Nueva Visión.

Levitsky S. \& Way, L. (2010). Competitive Authoritarianism: Hybrid Regimes After the Cold War. Cambridge: Cambridge University Press.

Linz, J. (2000). Totalitarian and authoritarian regimes. London: Lynne Rienner Publishers.

Luhmann, N. (1992). Die Wissenschaft der Gesellschaft. Frankfurt am Main: Suhrkamp.

Luhmann, N. (1993). Individuum, Individualität, Individualismus. In N. Luhmann, Gesellschaftsstruktur und Semantik 3 (pp. 149-258). Frankfurt am Main: Suhrkamp.

Luhmann, N. (1996). Tautologie und Paradoxie in den Selbstbeschreibungen der modernen Gesellschaft. In N. Luhmann, Protest (pp. 79-106). Frankfurt am Main: Suhrkamp.

Luhmann, N. (1997). Teoría política en el Estado de Bienestar. Madrid: Alianza Editorial. Luhmann, N. (1998a). Sistemas sociales. Barcelona: Anthropos.

Luhmann, N. (1998b). Die Gesellschaft der Gesellschaft. Frankfurt am Main: Suhrkamp.

Luhmann, N. (1999) Metamorphosen des Staates, In N. Luhmann, Gesellschaftsstruktur und Semantik 4 (pp. 135-136). Frankfurt am Main: Suhrkamp.

Luhmann, N. (2000). Die Politik der Gesellschaft. Frankfurt am Main: Suhrkamp.

Luhmann, N. (2005a). Poder. Barcelona: Anthropos. 
Luhmann, N. (2005b). Gesellschaftliche Grundlagen der Macht: Steigerung und Verteilung. In N. Luhmann, Soziologische Aufklärung 4 (pp. 121-130). Wiesbaden: VS Verlag.

Luhmann, N. (2006). Organisation und Entscheidung. Wiesbaden: VS Verlag.

Luhmann, N. (2007a). Komplexität und Demokratie. In N. Luhmann, Politische Planung. Aufsätze zur Soziologie von Politik und Verwaltung (pp. 35-45). Wiesbaden: VS Verlag.

Luhmann, N. (2007b). Die Knappheit der Zeit und die Vordringlichkeit des Befristeten. In N. Luhmann, Politische Planung. Aufsätze zur Soziologie von Politik und Verwaltung (pp. 143-165). Wiesbaden: VS Verlag.

Luhmann, N. (2007c). Politische Planung. In N. Luhmann, Politische Planung. Aufsätze zur Soziologie von Politik und Verwaltung (pp. 66-89). Wiesbaden: VS Verlag.

Luhmann, N. (2008). Ökologische Kommunikation. Kann die moderne Gesellschaft sich auf ökologische Gefährdungen einstellen? Wiesbaden: VS Verlag.

Luhmann, N. (2010). Politische Soziologie. Berlin: Suhrkamp.

Martín, G. (1983). Magia y religión en la Venezuela contemporánea. Caracas: Ediciones de Biblioteca UCV.

Martínez Meucci, M.A. (2012). Apaciguamiento. El Referéndum Revocatorio y la consolidación de la Revolución Bolivariana. Caracas: Editorial Alfa.

Mascareño, A. (2010). Diferenciación y contingencia en América Latina. Santiago de Chile: Ediciones Universidad Alberto Hurtado.

Oropeza, A. (2009). Comunicación como política de gobierno vs. Comunicación como política de revolución. En M. Bisbal (Ed.), Hegemonía y control comunicacional (pp. 61-84). Caracas: Editorial Alfa.

Pollak-Eltz, A. (2004). María Lionza, mito y culto venezolano. Caracas: UCAB.

Rabinbach, A. (2006). Moments of Totalitarianism. History and Theory 45, 72-100.

Romero, C. (2006). Jugando con el globo. La política exterior de Hugo Chávez. Caracas: Ediciones B.

Ruiz-Vargas, J. M. (2002). Memoria y olvido. Perspectivas evolucionista, cognitiva y neurocognitiva. Madrid: Trotta.

Rupnik, J. (1991). El totalitarismo visto desde el Este. En G. Hermet (ed.), Totalitarismos (pp. 50-83). México: FCE.

Salas de Lecuna, Y. (1987). Bolívar y la historia en la conciencia popular. Caracas: Universidad Simón Bolívar.

v. Foerster, H. (1993). Epistemologie der Kommunikation. In H. von Foerster, Wissen und Gewissen (pp. 269-281). Frankfurt am Main: Suhrkamp.

Voegelin, E. (2006) La nueva ciencia política. Una introducción. Buenos Aires: Katz Editores.

Zizek, S. (2001). Did Somebody Say Totalitarianism? London: Verso.

\section{SOBRE EL AUTOR}

José Javier Blanco, posee el gado de Licenciado en Estudios Políticos y Administrativos por la Universidad Central de Venezuela y es Doctor en Ciencias, mención Ciencias Políticas por la Universidad Central de Venezuela. Actualmente se desempeña como Profesor Agregado en el Departamento de Ciencias Sociales de la Universidad Simón 
Bolívar de Venezuela. Entre sus últimas publicaciones destacan: Observando la historia de las ideas. Niklas Luhmann y su contribución al debate contemporáneo de las ciencias históricas (Politeia, 2011) y Hacia una teoría operativa del significado (Ariadna histórica, 2012).

\section{CONTACTO}

Universidad Simón Bolívar

Valle de Sartenejas

Edificio de Estudios Generales, Tercer Piso.

Departamento de Ciencias Sociales.

Baruta 1086, Estado Miranda.

Teléfonos: +58 (212) 9063840 / 3841

joseblanco@usb.ve

Recibido: Septiembre 2015

Aceptado: Abril 2016 